\title{
A RARE CAUSE OF NEONATAL CYANOSIS - CONGENITAL METHEMOGLOBINEMIA - A CASE REPORT
}

\section{Pediatrics \\ Dr. Somasekar R Professor, Sree Balaji Medical College and Hospital, Chennai}

\section{ABSTRACT}

Cyanosis can occur at any age but it is a great challenge when it is in the newborn. Multiple causes have been established, and it usually is an ominous sign, especially when it occurs with neonatal sepsis or cyanotic congenital heart disease. Cyanosis caused by abnormal forms of hemoglobin can be life threatening, and early recognition is mandatory to prevent unnecessary investigations and delay in management. Abnormal hemoglobin newborn screening is a useful tool for the diagnosis. Acquired methemoglobinemia caused by environmental oxidizing agents, is common, but congenital deficiency of the innate reducing enzyme is so rare that only a few cases are documented in the medical literature around the world. Here I am presenting a case of a neonate with cyanosis as a result of congenital deficiency of cytochrome b5 reductase enzyme. This neonate was found to have cyanosis and appeared blue at newborn follow-up visit. Sepsis, congenital heart disease, prenatal administration, and ingestion of oxidant dyes were excluded as causes of the cyanosis by history, examination and appropriate tests. Chocolate discoloration of arterial blood provided a clue to the diagnosis. A normal newborn screen and hemoglobin electrophoresis made the diagnosis of hemoglobin M unlikely as the cause of the methemoglobinemia ( $\mathrm{Hb} \mathrm{A} \mathrm{58.9 \% ,} \mathrm{A2} \mathrm{1.9 \% ,} \mathrm{and} \mathrm{F} \mathrm{39.2 \% ).} \mathrm{Red} \mathrm{blood} \mathrm{cell} \mathrm{enzyme} \mathrm{activity} \mathrm{and} \mathrm{DNA} \mathrm{analysis} \mathrm{revealed} \mathrm{a}$ homozygous form of the cytochrome b5 reductase enzyme deficiency. She responded very well to daily methylene blue and ascorbic acid administration, and she has normal growth and developmental parameters, although she shows an exaggerated increase in her methemoglobin level.

\section{KEYWORDS}

\section{CASE REPORT}

A 20-day-old $2.8 \mathrm{~kg}$ infant was seen in the office for a routine postnatal follow-up visit. She was born at full term by spontaneous vaginal delivery to a 29-year-old mother with full antenatal care and no perinatal problems. Apgar score was 8 and 9 at 1 and 5 minutes, respectively. She was discharged from the hospital on the second day after her BCG, Hepatitis B and OPV immunization. She had been well since discharge and has been exclusively breastfed, her development had been appropriate. Her mother did not recognize her unusual colour and denied use of any medications. There is no parental consanguinity. Mild central cyanosis was noted on physical examination. Pulse oximetry was $87 \%$ in room air, so she was transferred to the NICU. In Neonatal Intensive Care Unit (NICU), the vital signs were $\mathrm{T}^{\circ} 99^{\circ} \mathrm{F}$, heart rate $182 / \mathrm{min}$, respiratory rate $36 / \mathrm{min}$, saturation on pulse oximetry $91 \%$ with fraction of inspired oxygen 1.0 and CBG of 78 $\mathrm{mg} / \mathrm{dL}$. Blood pressure measurement could not be obtained, despite rapid infusion of $20 \mathrm{~mL} / \mathrm{kg}$ crystalloid fluids. She continued to appear cyanotic and was electively intubated with a presumed diagnosis of septic shock and started on correction with IV Bolus. Septic screening was sent and appropriate cultures were obtained and broad-spectrum intravenous antibiotics was started.

Chest radiograph revealed a normal heart shadow with clear lung fields. Echocardiography confirmed a normal cardiac anatomy with adequate function. On obtaining femoral arterial access, her blood had a dark chocolate appearance despite documentation of arterial pulsations. Her initial hematocrit was $20 \%$, probably iatrogenic as a result of technical difficulty in obtaining vascular access and multiple fluid boluses, so she was given a $20 \mathrm{~mL} / \mathrm{kg}$ packed red blood cell (PRBC) transfusion, which improved her hematocrit to $30 \%$.

Arterial blood gas analysis revealed a $\mathrm{pH} 7.43 / \mathrm{Paco}_{2} 37 / \mathrm{PaO}_{2}$ $340 / \mathrm{HCO}_{3} 23 /$ base deficit -2 with a calculated hemoglobin saturation of $100 \%$ on fraction of inspired oxygen 1.0. Serum lactic acid was 1.3 $\mathrm{mmol} / \mathrm{L}$. Serum methemoglobin level was $28.0 \%$ and carboxyhemoglobin was $0.3 \%$ by co-oximetry. There was no clinical or culture support for sepsis, and she was quickly weaned off the ventilator and extubated to room air, which she tolerated very well with oxygen saturations on pulse oximetry ranging between $87 \%$ and $94 \%$. She received methylene blue $2 \mathrm{mg} / \mathrm{kg}$ on the second day of admission. She tolerated the dose without side effects. Methemoglobin level 12 hours after the methylene blue was $7.7 \%$ dropping to $1.4 \% 24$ hours after the medication.

Over the next 3 days she was monitored in the NICU, her methemoglobin level increased to $27.9 \%$ with no change in her clinical status.

At this point, a deficiency in reduced nicotinamide adenine dinucleotide (NADH)-cytochrome b5 reductase was suspected, and whole blood samples from the infant and her parents were obtained. The samples were analyzed for cytochrome b5 reductase (methemoglobin reductase B) enzyme activity. This assay was performed spectrophotometrically by measuring the oxidation of $\mathrm{NADH}$. His initial enzyme activity level was $7.1 \mathrm{IU} / \mathrm{g}$ (n 10.1-19.4 $\mathrm{IU} / \mathrm{g}$ ). This level, although low according to the established range was falsely elevated as a result of the PRBC transfusion. The enzyme activity level was repeated after 3 months, an adequate interval for destruction of most of the transfused PRBC. The repeat level was 4.2 $\mathrm{IU} / \mathrm{g}$. This is consistent with a homozygous deficiency of the cytochrome b5 reductase enzyme.

The infant was started on daily oral methylene blue $(1.5 \mathrm{mg} / \mathrm{kg})$ and ascorbic acid $(5 \mathrm{mg} / \mathrm{kg})$. Methemoglobin level remained $4.8 \%$, and she was discharged from the hospital with only mild central cyanosis.

\section{DISCUSSION}

Methemoglobin is produced from oxidation of ferrous iron $\left(\mathrm{Fe}^{2+}\right)$ to ferric iron $\left(\mathrm{Fe}^{3+}\right)$ within the heme moiety of hemoglobin. Methemoglobin, which normally constitutes $<1 \%$ of the total hemoglobin, cannot carry oxygen. There's increased affinity for oxygen at the remaining binding sites, causing a left shift in the oxygen dissociation curve. ${ }^{3}$ This cause decrease oxygen delivery to tissue.

Enzyme responsible for reducing methemoglobin in normal erythrocytes called NADH-requiring enzyme diaphorase. Now generally referred to as NADH-cytochrome $\mathrm{b} 5$ reductase, a functional deficiency in this enzyme is universally recognized as the underlying cause of congenital methemoglobinemia. Hereditary enzymopenic methemoglobinemia could be stratified into 4 distinct classes or types. Type 1, the most common and least debilitating, involves a deficiency in cytochrome b5 reductase limited to erythrocytes. Type 2 congenital methemoglobinemia is more pervasive and is associated with a generalized systemic deficiency affecting a multitude of tissue, type 3 hereditary enzymopenic methemoglobinemia

Individuals with congenital methemoglobinemia will typically present with cyanosis in the neonatal period. In managing a cyanotic patient, physicians will often obtain an arterial blood gas analysis, in addition to monitoring pulse oximetry. Unfortunately, the patient with methemoglobinemia will of- ten have normal values for both.

Unlike a pulse oximeter, which measures light absorbance at 2 wavelengths $(660 \mathrm{~nm}$ and $940 \mathrm{~nm}$, corresponding to the absorption of oxyhemoglobin and deoxyhemoglobin, respectively), a co-oximeter measures light absorbance at 4 different wave- lengths. These wavelengths correspond to the ab- sorption characteristics of deoxyhemoglobin, oxyhemoglobin, carboxyhemoglobin, and methemoglobin. 
Once the diagnosis of methemoglobinemia has been made, there are various assays available to quantify NADH-cytochrome b5 reductase activity. ${ }^{2}$ Adult levels of enzyme function are attained by 2 to 3 months of age, and in the neonate, methemoglobin reductase levels are normally $60 \%$ of the normal adult value.

Methylene blue is the treatment of choice for severe methemoglobinemia. ${ }^{2}$ In the presence of nicotinamide adenine dinucleotide phosphate (NADPH), methylene blue is converted to leucomethylene blue, which results in nonenzymatic reduction of methemoglobin. ${ }^{2}$ Ascorbic acid directly re- duces methemoglobin, but the rate of the reaction is too slow for it to be effective when used alone. ${ }^{8}$ Finally, if the combination of ascorbic acid and methylene blue fails to reduce the methemoglobin level, then hyperbaric oxygen and exchange transfusions are alternative therapy.

Our patient demonstrated all of the classical features of congenital methemoglobinemia on presentation. He was treated in the emergency department as a child in septic shock as a result of the usual presentation of a rare disease. His initial level of the cytochrome b5 reductase enzyme level was skewed as a result of the PRBC transfusion. A repeat level 3 months after the transfusion revealed his actual enzyme level of 4.2. It is impossible at this point to determine whether he will be classified as having type 1 or 2 . This has significant prognostic implications, and full genetic analysis of the family is in progress. In summary, congenital methemoglobinemia is a very rare but treatable cause of neonatal cyanosis th0at should be considered in the differential diagnosis of cyanosis and septic shock in the neonatal period.

\section{REFERENCES}

1. Griffey RT, Brown DM, Nadel ES. Cyanosis. J Emerg Med. 2000;18: 369-371

2. Wright RO, Lewander WJ, Woolf AD. Methemoglobinemia: etiology, pharmacology, and clinical management. Ann Emerg Med. 1999;34: 646-656

3. Baraka AS, Ayoub CM, Kaddoum RN, Maalouli JM, Chehab IR, Hadi UM. Severe oxyhemoglobin desaturation during induction of anesthe- sia in a patient with congenital methemoglobinemia. Anesthesiology. 2001;95:1296-1297

4. Pollack ES, Pollack CV. Incidents of subclinical methemoglobinemia in infants with diarrhea. Ann Emerg Med. 1994;24:652-656

5. Sager S, Grayson G, Feig S. Methemoglobin associated with acidosis of probable renal origin. JPediatr. 1995;126:59-61

6. Francois. Cas de cyanose congeniale sans cause apparente. Bull Acad Roy Med Belg. $1845 ; 4: 698$

7. Jaffe ER, Hultquist DE. Cytochrome b5 reductase deficiency and enzy- mopenic hereditary methemoglobinemia. In: Scriver CR, Beaudet AL, Sly WS, et al, eds. The Metabolic and Molecular Basis of Inherited Disease. 7th ed. New York, NY: McGrawHill; 1995:2267-2280

8. Scott EM. The relation of diaphorase of human erythrocytes to inheri- tance of methemoglobinemia. J Clin Invest. 1960;39:1176-1179

9. Hitzenberger K. Autotoxische zyanose (intraglobulare methamoglobi- namie). Wien Arch Intern Med. 1932;23:85 